\title{
Explorando la ciudad: visualidades cotidianas en Temuco, La Araucanía, Chile.
}

\author{
Exploring the city: daily visualities in Temuco, La Araucania, Chile.
}

\section{Juan Erick Patricio Carrera* \\ Universidad Católica de Temuco, Chile \\ patriciocarrera.a@gmail.com}

La presente obra se enmarca dentro de un proceso de reflexión antropológica que implica un ejercicio de descotidianización para observar críticamente la composición estructural de la ciudad mediante la subjetividad de lo humano y la expresión fotográfica. Por lo tanto, los documentos, textos, aquí presentados hacer parte de una triangulación que involucra la reflexión antropológica y la técnica de la Street photography, que pretende otorgar al espectador una referencia poli-significacional, interpretativa, de la realidad cotidiana de la ciudad de Temuco, desde la espontaneidad que el caminar en la ciudad ofrece y desde la incertidumbre propia de explorar con otro nivel de observación la vida cotidiana.

Así, el trabajo realizado converge en un relato sociofotográfico que imprime de alguna forma parte de la esencia de la ciudad, desde las realidades de su gente, desde un punctum que nos mueve como antropólogas y antropólogos entre las formas socioculturales en sus diversas dimensiones, intentando emplazar al espectador a realizar una reflexión profunda, analógica, sobre la realidad social del contexto sureño de un Chile que vive la interculturalidad desde su constitución, pero que se ha negado constantemente a sí mismo mediante las diversas metáforas de la globalización.

De esta forma, la presente muestra es una re-presentación de la realidad que sólo intenta ser un puente crítico y reflexivo para que el lector (visual) se interiorice, aunque sea mínimamente, en la espontaneidad de la vida cotidiana en este rincón del fin del mundo. Para ello, he de presentar una serie de imágenes que nos dan cuenta implícita de ciertas dimensiones sociales complejas; la marginación, la ruralidad, la religiosidad, las costumbres, entre otras, y que a través de un discurso mimético en primera persona generan un esquema de relaciones sobre un marco estructural amplio de lo sociocultural en la región.

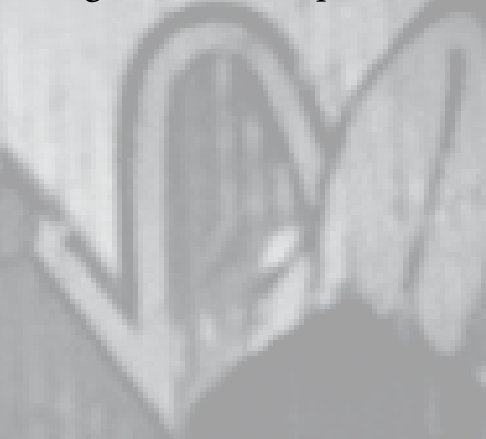

* Licenciado en antropología y Fotógrafo documental, Facultad de Ciencias Sociales y Humanidades, Universidad Católica de Temuco. Investigador, ha publicado diversos artículos científicos y expuesto en congresos sobre antropología de lo imaginario, semiótica y fotografía social.

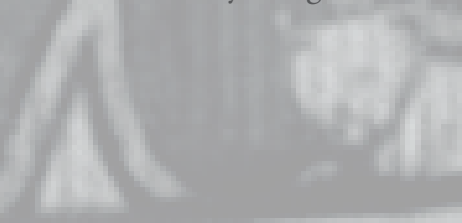




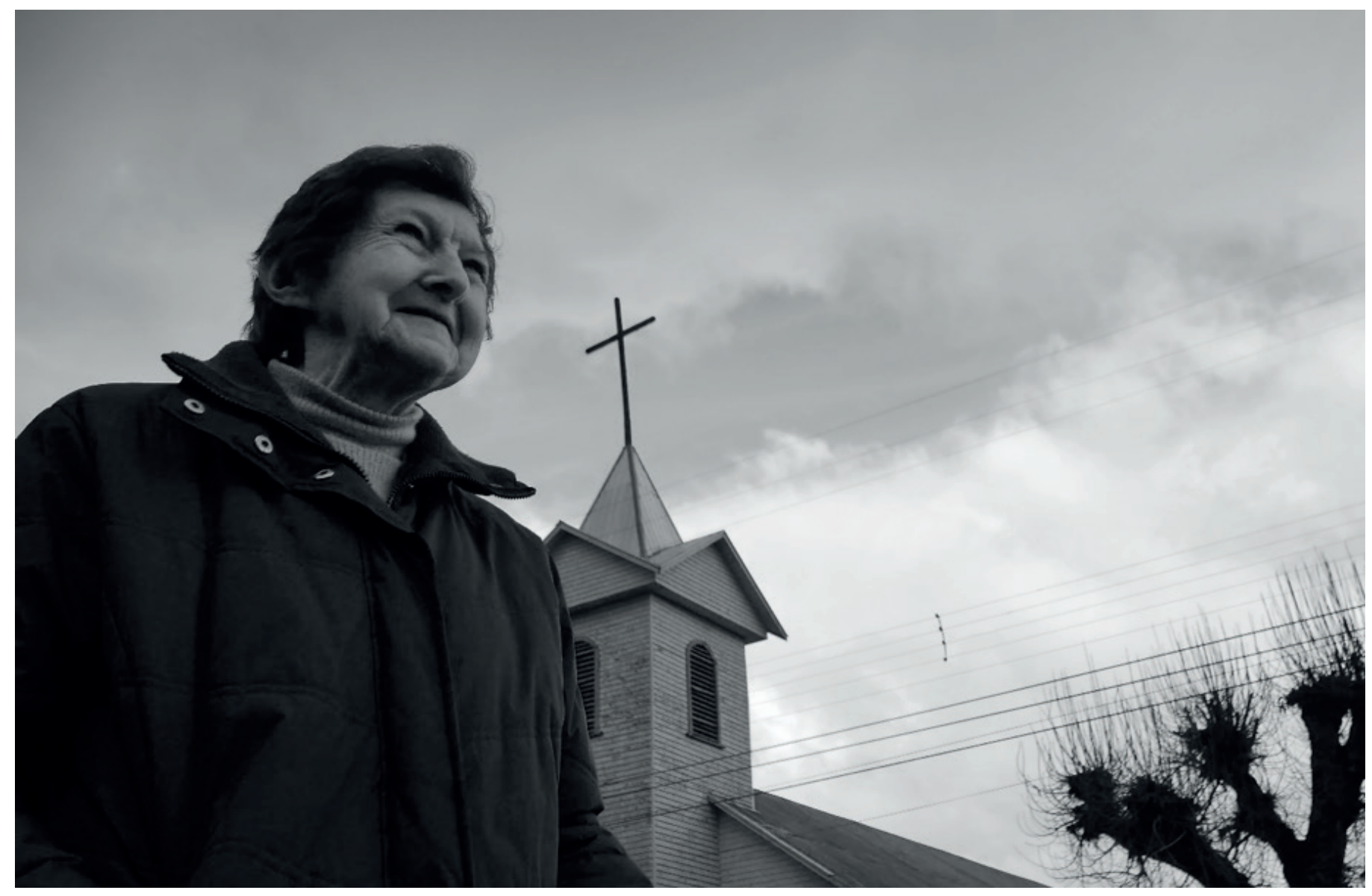

Religiosidad 


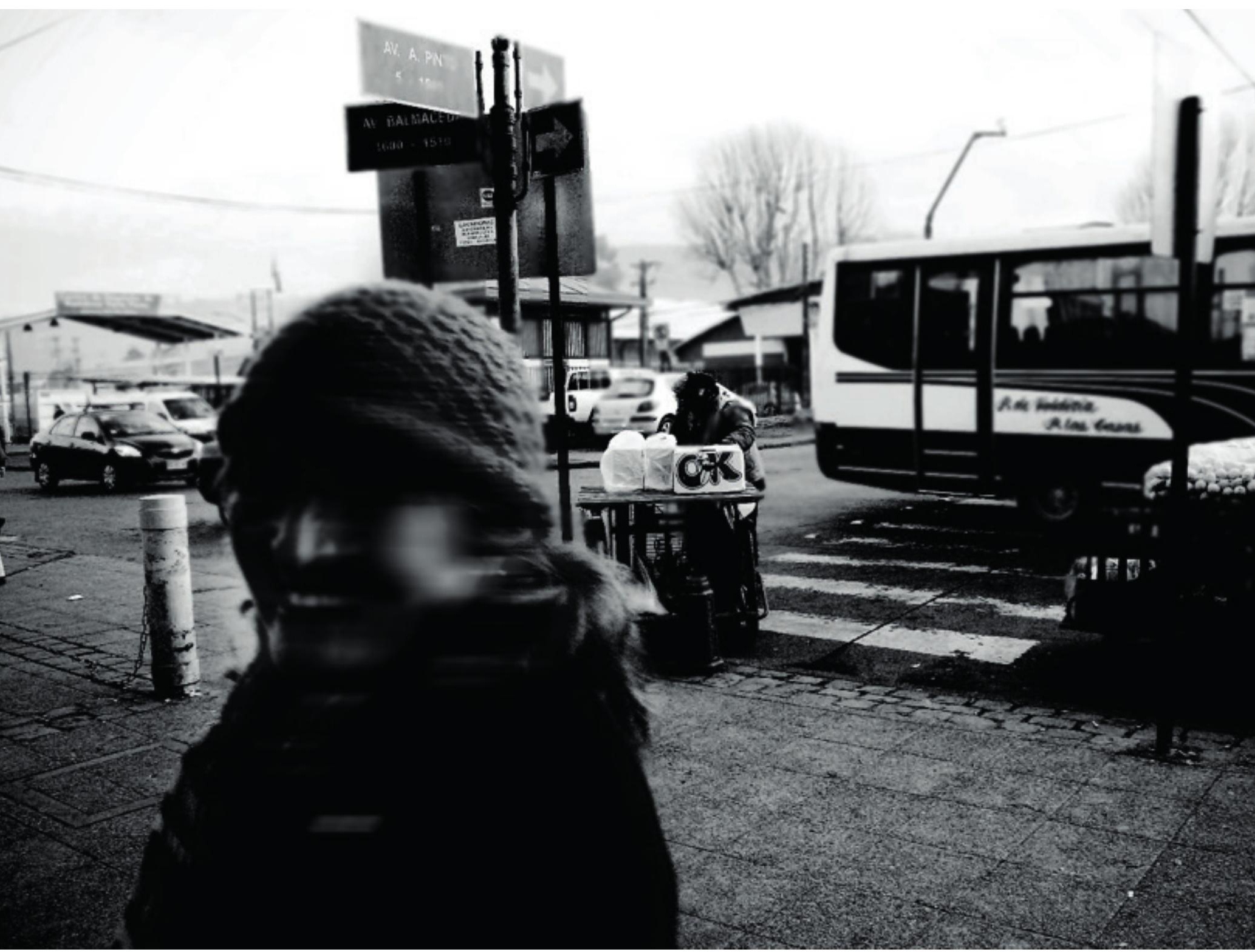

Espontaneidad 


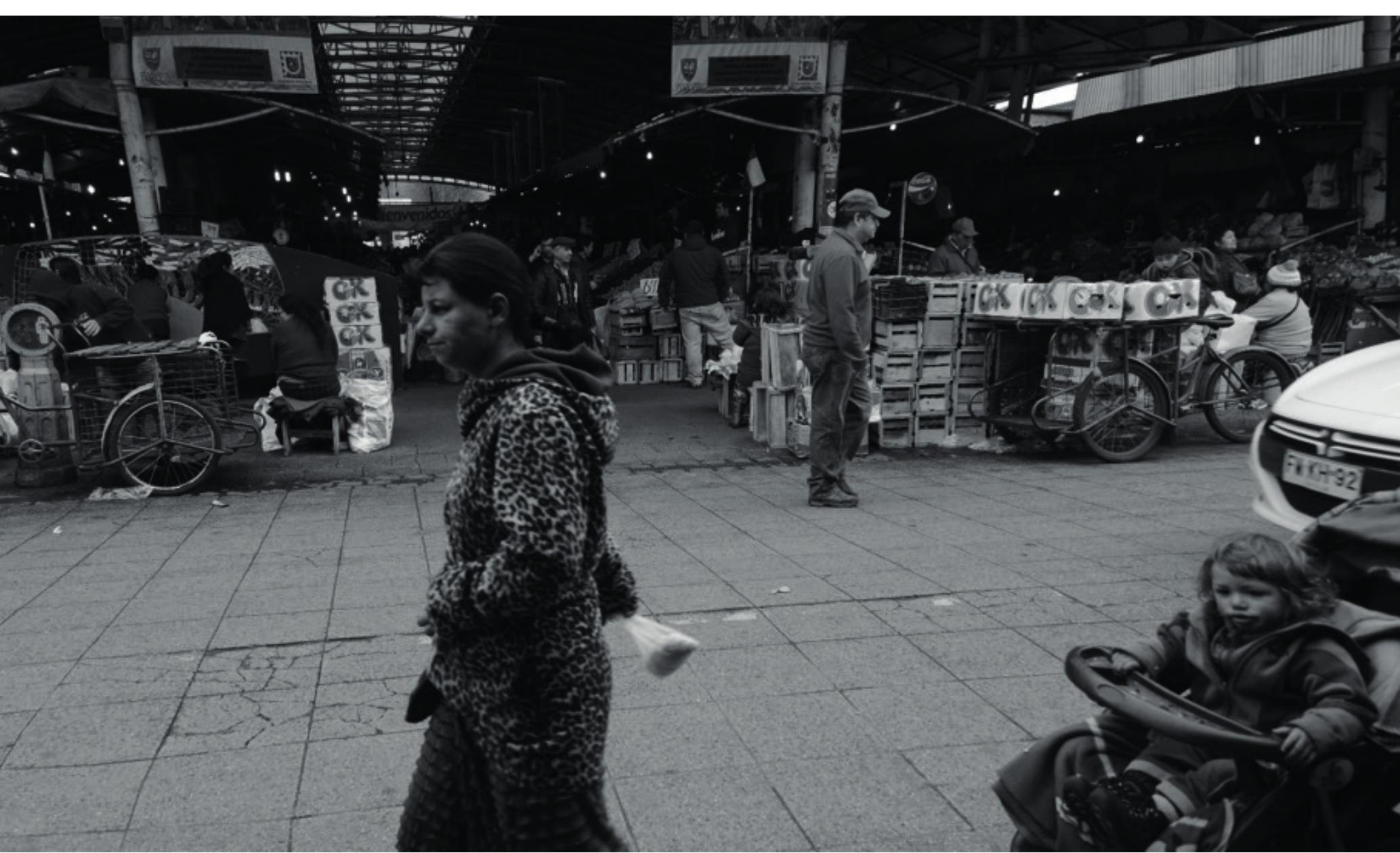

Multiculturalidad 


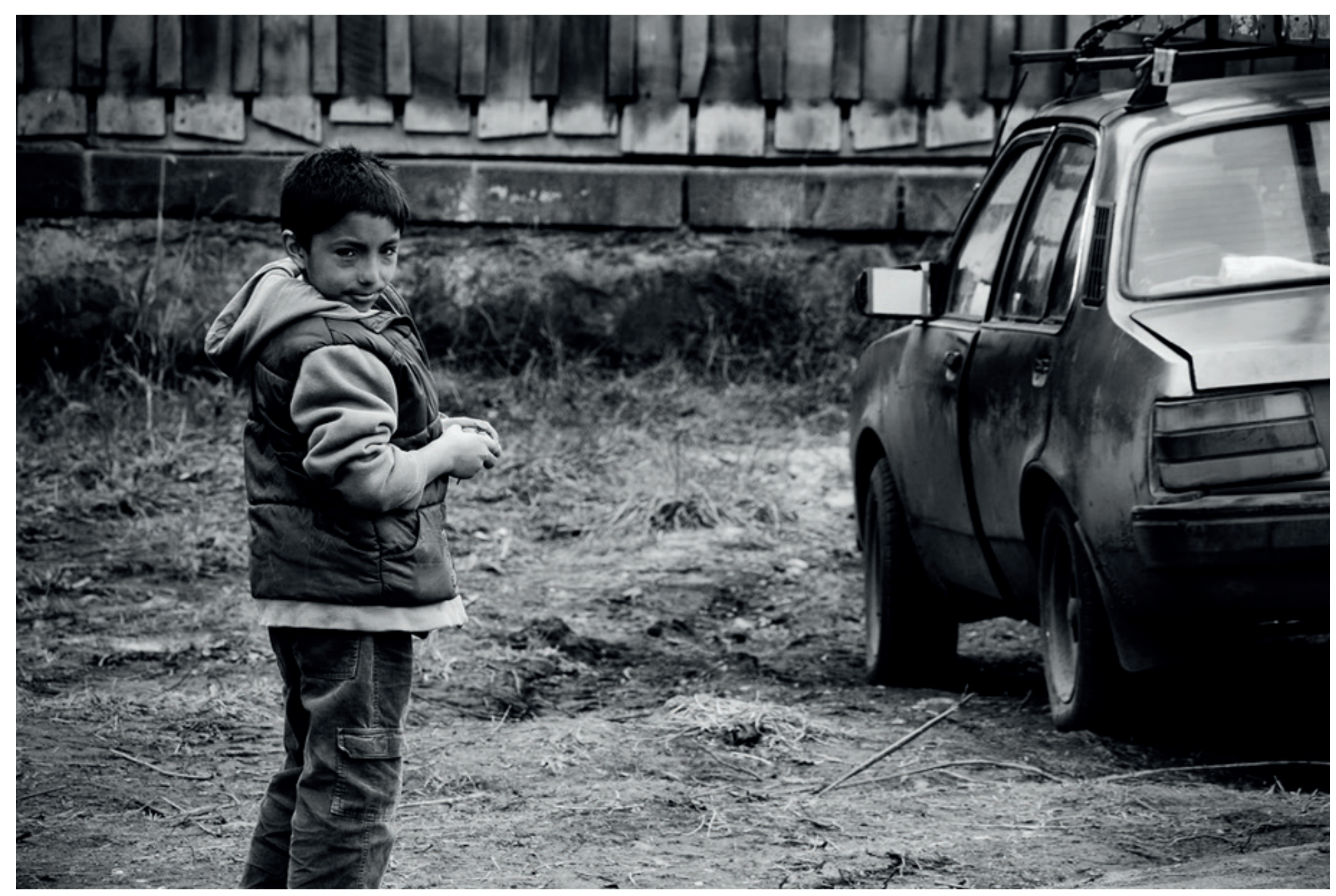

Segregación 
Periurbanidad

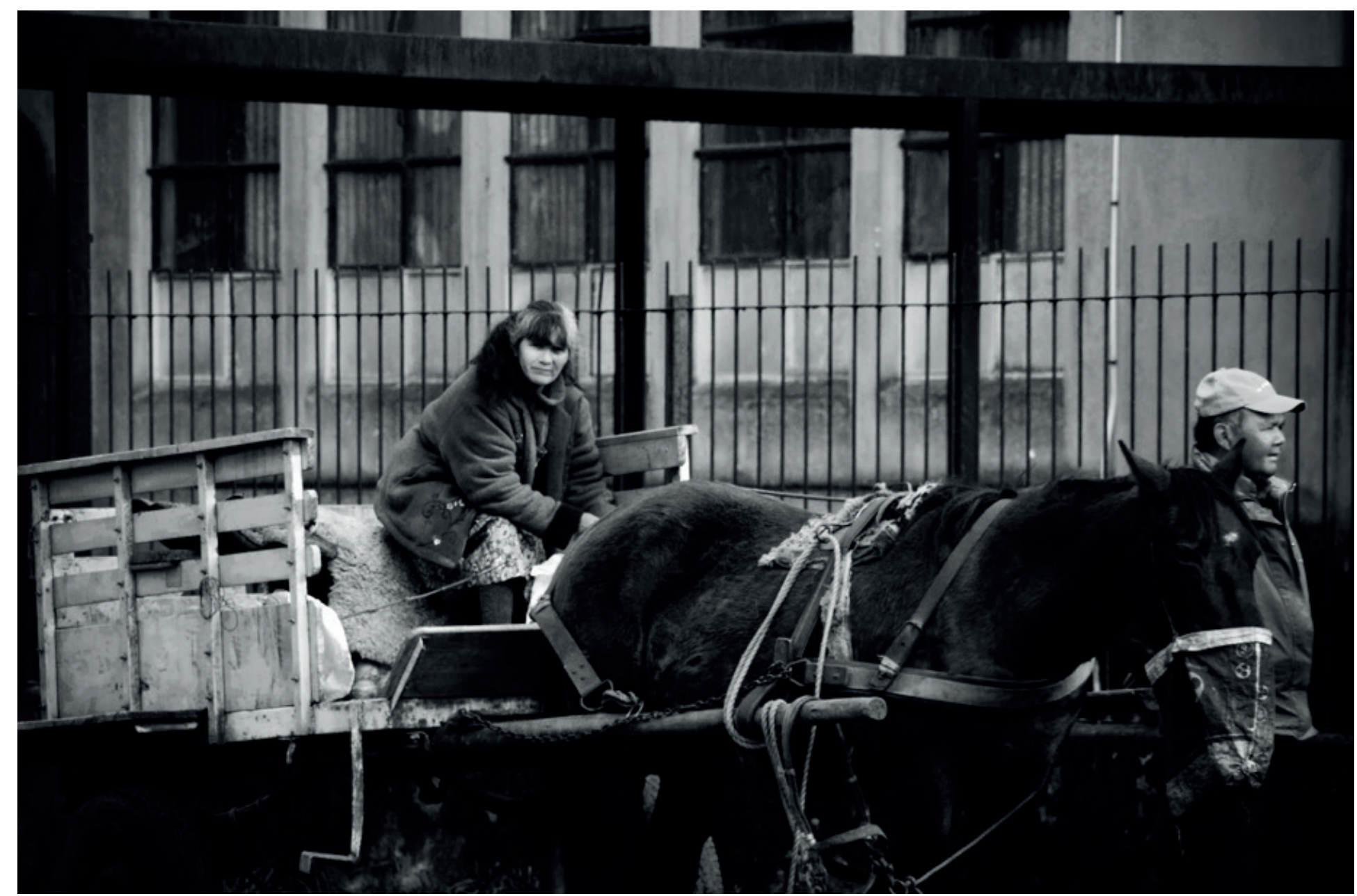




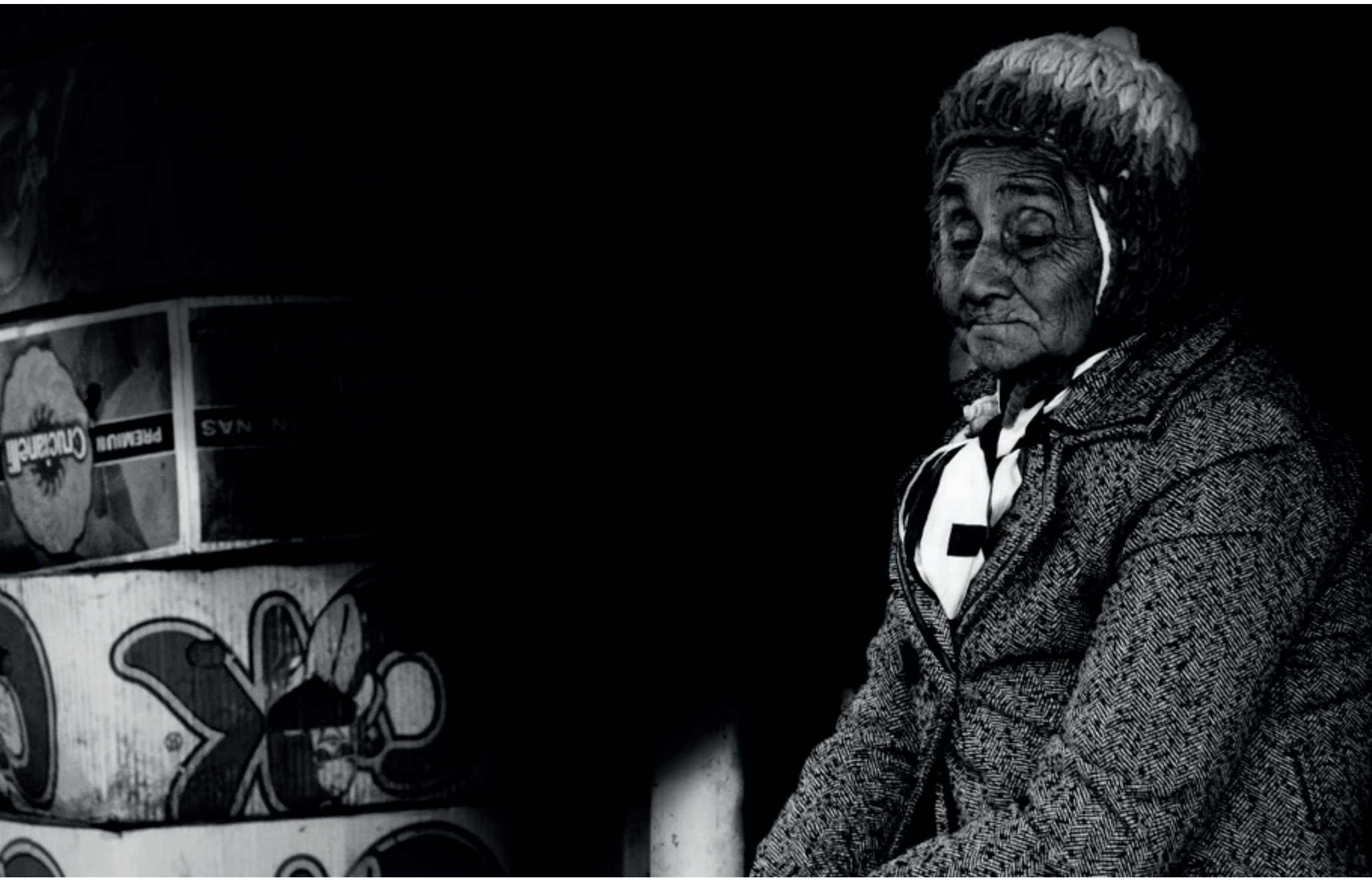




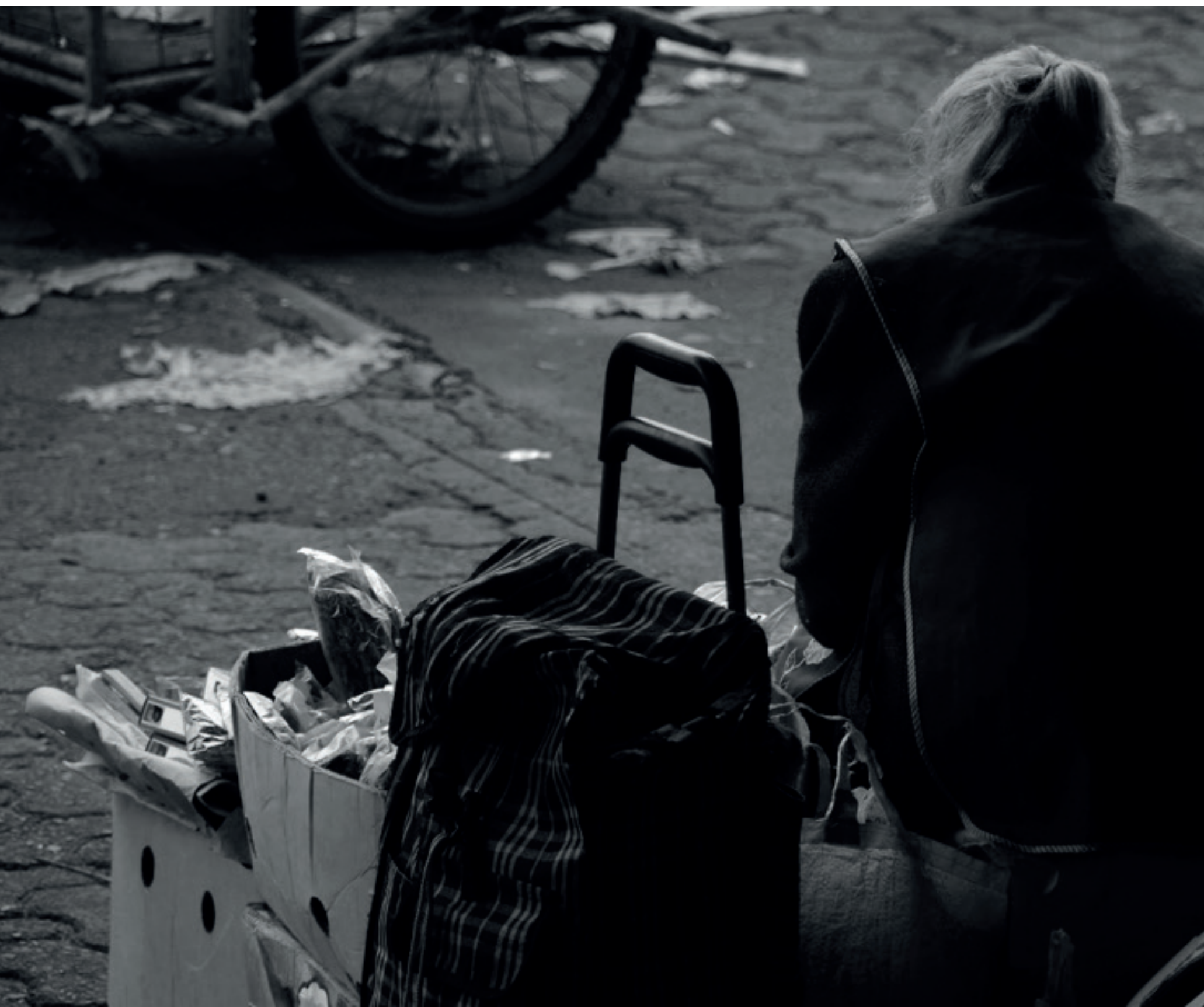




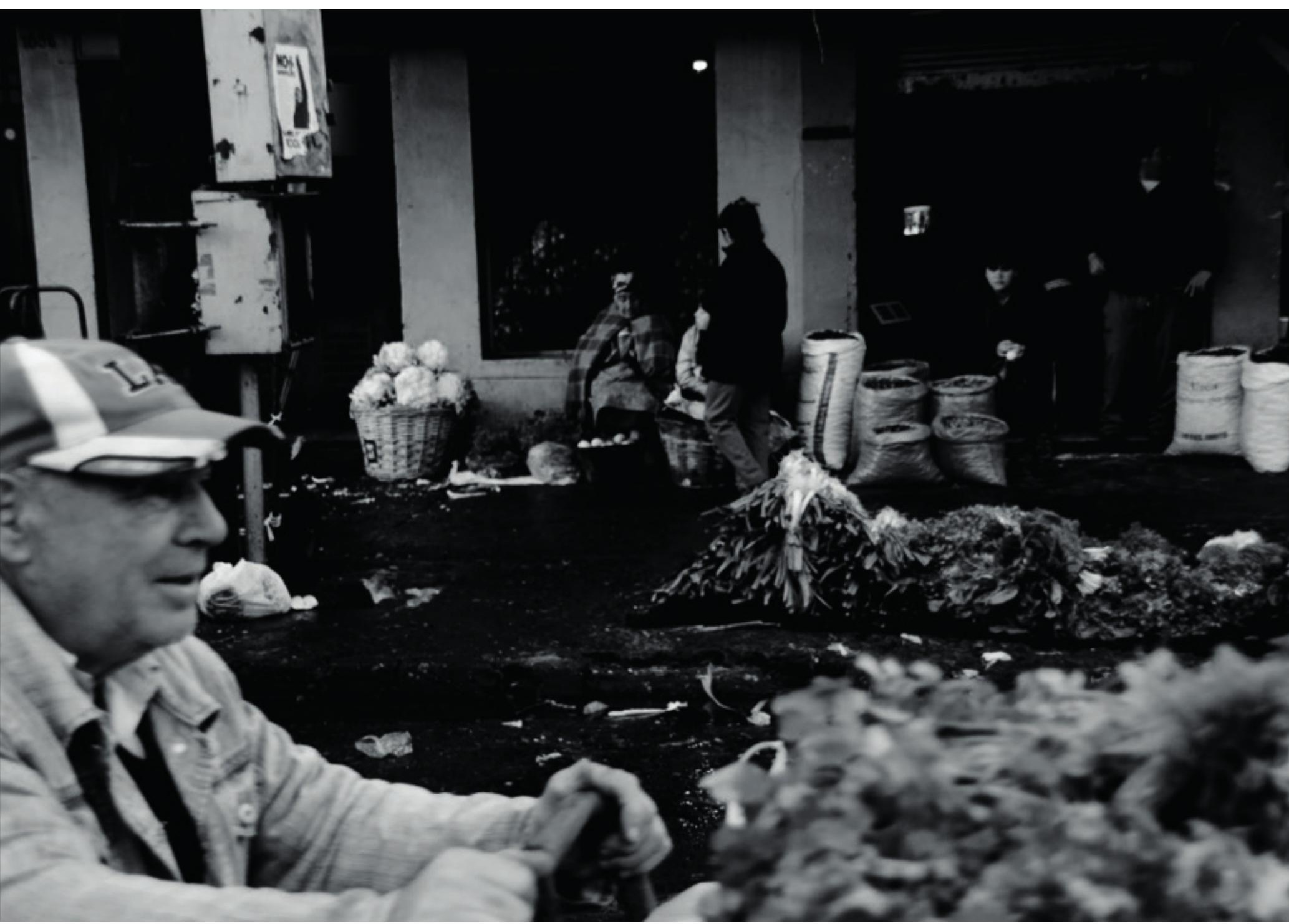


Ruralidad

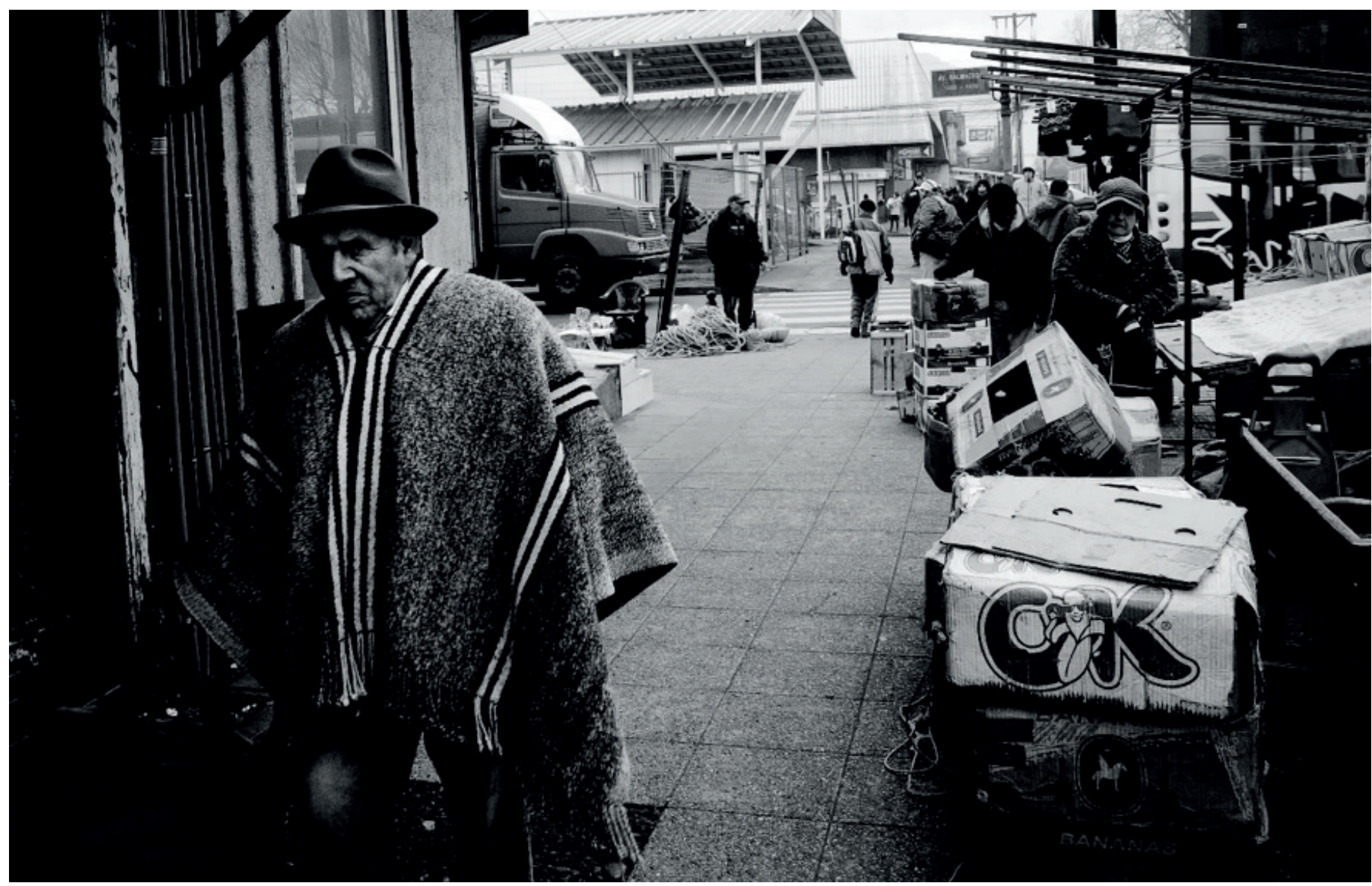

